\title{
Predictors of Left Ventricular Hypertrophy and Their Cutoffs in Peritoneal Dialysis Patients
}

\author{
Kamal Hassan, ${ }^{1,2}$ MD, Shadi Hassan, ${ }^{3}$ MD, Saab Anwar, ${ }^{4}$ MD, Armaly Zaher,${ }^{5}$ MD, \\ Rabia EDGEM, ${ }^{2}$, and Fadi Hassan, ${ }^{6}$ MD
}

\begin{abstract}
SUMMARY
Cardiovascular complications are the main cause of morbidity and mortality in peritoneal dialysis (PD) patients. Left ventricular hypertrophy (LVH) is a major predictor of the development of cardiovascular events. This study aimed to identify risk factors that contribute to the development of LVH and to determine their cutoffs in patients on maintenance peritoneal dialysis.

In this cross sectional study we evaluated the association of 23 variables including age, PD vintage, ultrafiltration, urine volume, residual renal function, mean daily SBP, mean daily DBP, fasting glucose, HbA1c, peritoneal glucose load index (PGLI), fluid overload (FO), plasma brain natriuretic peptide (BNP), plasma hsCRP and IL-6, serum albumin, white blood cell (WBC) count, hemoglobin, hematocrit, triglycerides, LDL-C (low density lipoprotein cholesterol), HDL-C (high density lipoprotein cholesterol), and PTH with LVH in 38 stable patients on maintenance PD $\geq 24$ months.

LVH was detected in $57.9 \%$ of patients. Logistic regression and receiver operating characteristics (ROC) analysis revealed that HbA1c, PGLI, FO, plasma BNP, hsCRP and IL-6 seem to be possible predictors of LVH. The cutoffs associated with the presence of LVH were: $7.5 \%, 3.2 \mathrm{~g} / \mathrm{kg} /$ day, $1.7 \mathrm{~L}, 330 \mathrm{pg} / \mathrm{mL}, 7.5 \mathrm{mg} / \mathrm{dL}$ and $3.3 \mathrm{pg} / \mathrm{mL}$ for $\mathrm{HbA} 1 \mathrm{c}$, PGLI, FO, plasma BNP, hsCRP and IL-6, respectively (sensitivity 72.8 to $81.8 \%$ and specificity 75.0 to $93.8 \%$ ).

The results suggest that efforts should be made to reduce the peritoneal glucose load (PGL), to improve the hydration status, and to attenuate the inflammatory process in order to reduce the risk of the development of LVH among PD patients. (Int Heart J 2015; 56: 186-191)
\end{abstract}

Key words: Fluid overload, Glucose load, Inflammation, Left ventricular mass

$\mathrm{C}$ ardiovascular (CV) complications are the main cause of morbidity and mortality in peritoneal dialysis (PD) patients. ${ }^{1)}$ Traditional [ie, diabetes mellitus (DM), dyslipidemia, hypertension], uremic [ie, fluid overload (FO)] and novel risk factors (ie, inflammation) contribute to early coronary atherosclerosis in PD patients. ${ }^{1)}$ Left ventricular hypertrophy (LVH) is a major predictor of the development of $\mathrm{CV}$ events independent of regular CV risk factors, both in the general public and in patients suffering from renal insufficiency. ${ }^{2)}$ This study aimed to identify risk factors that predict the development of LVH and to determine their cutoffs in patients on maintenance peritoneal dialysis.

\section{Methods}

Study design: In this cross sectional study we evaluated the influence of 23 variables including age, PD vintage, ultrafiltration, mean daily SBP, mean daily DBP, fasting glucose, HbA1c, peritoneal glucose load index (PGLI), fluid overload
(FO), plasma brain natriuretic peptide (BNP), plasma hsCRP and IL-6, serum albumin, white blood cell (WBC) count, hemoglobin, hematocrit, triglycerides, LDL-C (low density lipoprotein cholesterol), HDL-C (high density lipoprotein cholesterol), and PTH on left ventricular mass (LVM) in 38 stable patients on maintenance PD $\geq 24$ months. The characteristics of the study population are summarized in Table I. The study was approved by the Medical Ethics Committee of Western Galilee Hospital, Naharyia, Israel. All patients signed a written informed consent form before participating in the study. Age under 18 years, pregnancy, psychiatric disorders, "low" and "high" transporters, ultrafiltration failure, active coronary artery disease, heart failure (New York Heart Association [NYHA] class III or IV), any evidence of infection in the past 3 months, immunosuppressive therapy, liver cirrhosis, malignancy, patients with pacemakers, defibrillators, artificial joints, and pins or amputations were considered exclusion criteria. All subjects followed their usual recommended diet and continued their regular medications and PD regimen.

Assessment of residual renal function (RRF): Renal weekly

From the ${ }^{1}$ Faculty of Medicine in the Galilee, Bar-Ilan University, Safed, ${ }^{2}$ Department of Nephrology and Hypertension, Peritoneal Dialysis Unit, Western Galilee Hospital, Nahariya, ${ }^{3}$ Department of Internal Medicine, Carmel Medical Center, ${ }^{4}$ Clalit Health Services, Haifa, ${ }^{5}$ Edinburgh Medical Missionary Society, Nazareth, and ${ }^{6}$ Tel Aviv University, Tel Aviv, Israel.

Address for correspondence: Kamal Hassan, MD, Department of Nephrology and Hypertension, Peritoneal Dialysis Unit, Western Galilee Hospital - Nahariya, POB

21, Nahariya 22100, Israel. E-mail: drkamalh@ hotmail.com or Kamal.Hassan@naharia.health.gov.il

Received for publication July 30, 2014. Revised and accepted September 3, 2014.

Released in advance online on J-STAGE February 23, 2015.

All rights reserved by the International Heart Journal Association. 
Table I. Characteristics of the Study Population

\begin{tabular}{lc}
\hline Variable & Values \\
\hline Age (years) & $58.2 \pm 12.4$ \\
PD vintage (months) & $46.8 \pm 10.3$ \\
Male/Female & $20 / 18$ \\
CAPD/APD & $22 / 16$ \\
Residual renal function (mL/minute/1.73 m²) & $9.2 \pm 2.8$ \\
Kt/V & $2.1 \pm 0.4$ \\
High average/Low average transporters & $21 / 17$ \\
Glucose based PD solutions & 38 \\
Baxter Healthcare Ltd PD solutions & 20 \\
Fresenius Medical Care PD solutions & 18 \\
Primary renal disease & \\
Diabetes mellitus & 19 \\
Hypertension & 9 \\
Chronic glomerulopathy & 4 \\
Adult polycystic kidney disease & 3 \\
Alport syndrome & 1 \\
Unknown etiology & 2 \\
\hline
\end{tabular}

PD indicates peritoneal dialysis; CAPD, continuous ambulatory peritoneal dialysis; and APD, automated peritoneal dialysis.

$\mathrm{Kt} / \mathrm{V}$, renal weekly creatinine clearance, urine volume, and the average of 24-hour urine urea and creatinine clearance may be used as the indices of RRF in PD patients. In the present study the RRF was calculated as the average of 24-hour urine urea and creatinine clearance $\left(\mathrm{mL} /\right.$ minute $\left./ 1.73 \mathrm{~m}^{2}\right) .{ }^{3,4)}$

Assessment of the hydration status: The hydration status was assessed using a whole-body bioimpedance spectroscopy technique with a Fresenius Medical Care Body Composition Monitor device (Bad Homburg, Germany). ${ }^{3)}$ FO is defined by an increase in $\mathrm{FO}>1.0 \mathrm{~L}$.

Assessment of PGL: PGL was assessed using a novel PGL index (PGLI) (g/kg/day) referring to the net glucose content (monohydrated or unhydrated) (g) in the PD solutions administered in the daily PD prescription divided by the dry body weight (kg) assessed by whole-body bioimpedance spectroscopy:

$\operatorname{PGLI}(\mathrm{g} / \mathrm{kg} /$ day $)=$

Daily glucose content in peritoneal dialysis solutions ( $\mathrm{g}$ )

Dry weight assessed by bioimpedance spectroscopy (kg)

Assessment of LVM: LVM was assessed by calculating the LVM index (LVMI) using the Devereux formula: ${ }^{4)}$

$\begin{aligned} \operatorname{LVMI}\left(\frac{\mathrm{g}}{\mathrm{m}^{2}}\right)= & \left\{0.8\left[(\mathrm{IVST}+\mathrm{LVPWT}+\mathrm{LVEDD})^{3}-(\mathrm{LVEDD})^{3}\right]\right. \\ & +0.6\} / \text { Body surface }\end{aligned}$

[Interventricular septal thickness (IVST), left ventricular posterior wall thickness (LVPWT) and left ventricular end diastolic diameter (LVEDD)]. LVH is defined by an increase in LVMI $>95 \mathrm{~g} / \mathrm{m}^{2}$ in women and $>115 \mathrm{~g} / \mathrm{m}^{2}$ in men., ${ }^{5,6)}$

Statistical methods: Quantitative variables are presented as the mean and standard deviation and qualitative variables as frequencies and percentages. Correlations between age, PD vintage, ultrafiltration, urine volume, RRF, D/P creatinine, mean daily SBP, mean daily DBP, fasting glucose, HbA1c, PGLI, FO, plasma BNP, hsCRP and IL-6, serum albumin, WBC count, hemoglobin, hematocrit, triglycerides, LDL-C, HDL-C as well as PTH, and LVMI were determined using the
Table II. Mean \pm SD Values of All Tested Variables

\begin{tabular}{|c|c|}
\hline Variable & Mean $\pm \mathrm{SD}$ \\
\hline \multicolumn{2}{|l|}{ Glucose load } \\
\hline HbA1c $(\%)$ & $7.2 \pm 1.3$ \\
\hline PGLI (g/kg/day) & $3.3 \pm 1.1$ \\
\hline Fasting glucose (mg/dL) & $121.4 \pm 21.3$ \\
\hline \multicolumn{2}{|l|}{ Hydration status } \\
\hline $\mathrm{BNP}(\mathrm{pg} / \mathrm{mL})$ & $528.1 \pm 278.1$ \\
\hline $\mathrm{FO}(\mathrm{L})$ & $2.3 \pm 1.3$ \\
\hline Ultrafiltration (mL/day) & $2140.8 \pm 478.1$ \\
\hline Urine volume (mL/day) & $1104.0 \pm 719.6$ \\
\hline $\mathrm{RRF}\left(\mathrm{mL} / \mathrm{minute} / 1.73 \mathrm{~m}^{2}\right.$ ) & $8.6 \pm 2.8$ \\
\hline \multicolumn{2}{|l|}{ Inflammation } \\
\hline hsCRP (mg/dL) & $10.9 \pm 3.7$ \\
\hline IL-6 (pg/mL) & $4.4 \pm 1.4$ \\
\hline $\mathrm{WBC} / \mathrm{mm}^{3}$ & $8018 \pm 2141$ \\
\hline Albumin (g/dL) & $3.5 \pm 0.4$ \\
\hline \multicolumn{2}{|l|}{ Blood pressure } \\
\hline 24h SBP (mmHg) & $144.3 \pm 16.1$ \\
\hline 24h DBP (mmHg) & $79.1 \pm 7.0$ \\
\hline \multicolumn{2}{|l|}{ Lipid profile } \\
\hline Triglycerides & $194.0 \pm 61.7$ \\
\hline LDL-C & $119.4 \pm 12.1$ \\
\hline HDL-C & $39.0 \pm 5.6$ \\
\hline \multicolumn{2}{|l|}{ Renal anemia } \\
\hline Hemoglobin (g/dL) & $10.8 \pm 1.2$ \\
\hline Hematocrit (\%) & $33.7 \pm 8.1$ \\
\hline \multicolumn{2}{|l|}{ Others } \\
\hline Age (years) & $58.2 \pm 12.4$ \\
\hline PD vintage (months) & $46.8 \pm 10.3$ \\
\hline PTH (pg/mL) & $302.3 \pm 96.4$ \\
\hline \multicolumn{2}{|l|}{ LVM } \\
\hline $\operatorname{LVMI}\left(\mathrm{g} / \mathrm{m}^{2}\right)$ & $124.6 \pm 42.5$ \\
\hline
\end{tabular}

PGLI indicates peritoneal glucose index; BNP, plasma brain natriuretic peptide; FO, fluid overload; WBC, white blood cells; 24h SBP, 24 hour systolic blood pressure; $24 \mathrm{~h}$ DBP, 24 hour diastolic blood pressure; LDL$\mathrm{C}$, low density lipoprotein cholesterol; HDL-C, low density lipoprotein cholesterol; PD, peritoneal dialysis; PTH, parathyroid hormone; and LVMI, left ventricular mass index.

Pearson correlation coefficient test. Logistic regression was used to select independent determinants of LVH and then receiver operating characteristics (ROC) analysis was applied to assess the validity of these parameters in predicting $\mathrm{LVH}$.

\section{RESULTS}

The mean \pm SD of all tested variables including age, $\mathrm{PD}$ vintage, ultrafiltration, mean daily SBP, mean daily DBP, fasting glucose, HbA1c, PGLI, FO, plasma BNP, hsCRP and IL-6, serum albumin, WBC count, hemoglobin, hematocrit, triglycerides, LDL-C, HDL-C, and PTH are summarized in Tables I and II. LVH was detected in $57.9 \%$ (22/38) of patients. Mean daily SBP and DBP, HbA1c, PGLI, FO, plasma BNP, hsCRP and IL-6, WBC count, hemoglobin, triglycerides, LDL-C, and HDL-C all had significant positive linear correlations with LVMI (Table III). Urine volume, RRF, serum albumin, hemoglobin, hematocrit, and HDL-C had significant negative correlations with LVMI (Table III). No correlations were found between LVMI and age, PD vintage, ultrafiltration, D/P creatinine, or fasting glucose and PTH levels (Table III). The mean LVMI was similar in patients on maintenance CAPD as well 
as on APD $(122.1 \pm 55.0,127.1 \pm 42.5$, respectively, $(P=$ $0.755)$. The mean LVMI was also similar in high average transporter (HAT) and low average transporter (LAT)PD patients $(124.7 \pm 61.1,121.1 \pm 39.7$, respectively, $(P=0.458)$. Solute transport was analyzed as a continuous variable and no statistically significant correlation was found between the dialysate-to-plasma ratio of creatinine (D/P creatinine) values and LVMI ( $r=0.21, P=0.39)$.

Logistic regression analysis showed that $\operatorname{HbA1c}(P=$ $0.002)$, PGLI (parameters related to glucose load), $(P=0.007)$, FO $(P=0.007)$, plasma BNP $(P=0.011)$ (parameters related to the hydration status), hsCRP $(P=0.008)$, and IL-6 ( $P=$ $0.002)$ (parameters related to inflammation) were independently associated with LVH.

Table III. Correlations Between $t$ Tested Variables and LVMI (Pearson Correlation Coefficient Test)

\begin{tabular}{lcc}
\hline Variable & $r$ & $P$ \\
\hline Age & 0.145 & 0.386 \\
PD Vintage & 0.203 & 0.221 \\
Ultrafiltration & 0.221 & 0.361 \\
Urine volume & -0.41 & 0.03 \\
RRF & -0.39 & 0.04 \\
D/P creatinine & 0.21 & 0.39 \\
24h SBP & 0.563 & $<0.001$ \\
24h DBP & 0.400 & 0.013 \\
Fasting glucose & 0.198 & 0.189 \\
HbAlc & 0.765 & $<0.001$ \\
PGLI & 0.666 & $<0.001$ \\
FO & 0.778 & $<0.001$ \\
BNP & 0.782 & $<0.001$ \\
hsCRP & 0.745 & $<0.001$ \\
IL6 & 0.756 & $<0.001$ \\
Serum albumin & -0.625 & $<0.001$ \\
WBC & 0.528 & 0.001 \\
Hemoglobin & -0.698 & $<0.001$ \\
Hematocrit & -0.712 & $<0.001$ \\
PTH & 0.198 & 0.287 \\
Triglycerides & 0.681 & $<0.001$ \\
LDLC & 0.495 & 0.002 \\
HDLC & -0.469 & 0.002 \\
\hline PD & &
\end{tabular}

PD indicates peritoneal dialysis; RRF, residual renal function; 24h SBP, mean 24 hour systolic blood pressure; 24h DBP, mean 24 hour diastolic blood pressure; PGLI, peritoneal glucose load index, FO, fluid overload; BNP, plasma brain natriuretic peptide, WBC, white blood cells; LDL-C, low density lipoprotein cholesterol; HDL-C, low density lipoprotein cholesterol; PTH, parathyroid hormone; and LVMI, left ventricular mass index.
ROC curve analysis showed that HbA1c $(\mathrm{AUC}=0.84$, $95 \%$ confidence interval $=0.70-0.98, P<0.001)$, PGLI (AUC $=0.78,95 \%$ confidence interval $=0.62-0.93, P=0.005), \mathrm{FO}$ $(\mathrm{AUC}=0.86,95 \%$ confidence interval $=0.74-0.98, P<0.001)$, plasma $\mathrm{BNP}(\mathrm{AUC}=0.88,95 \%$ confidence interval $=0.78$ $0.99, P<0.001$ ), hsCRP (AUC $=0.89,95 \%$ confidence interval $=0.78-0.99, P<0.001)$, and IL-6 $($ AUC $=0.87,95 \%$ confidence interval $=0.75-0.99, P<0.001)$ were possible predictors of LVH (Table IV) (Figure).

The cutoffs for these risk factors that associated with LVH were: $7.5 \%, 3.2 \mathrm{~g} / \mathrm{kg} / \mathrm{day}, 1.7 \mathrm{~L}, 330 \mathrm{pg} / \mathrm{mL}, 7.5 \mathrm{mg} / \mathrm{dL}$ and $3.3 \mathrm{pg} / \mathrm{mL}$ for HbA1c, PGLI, FO, plasma BNP, hsCRP and IL-6, respectively (sensitivity 72.8 to 81.8 percent, specificity 75.0 to 93.8 percent) (Table IV).

The majority of patients with HbAlc $\geq 7.5 \%$ (72.7 percent), $\mathrm{PGLI} \geq 3.2 \mathrm{~g} / \mathrm{kg} /$ day (77.3 percent), $\mathrm{FO} \geq 1.7 \mathrm{~L}$ (72.7 percent), plasma $\mathrm{BNP} \geq 330 \mathrm{pg} / \mathrm{mL}$ (72.7 percent), hsCRP $\geq$ $7.5 \mathrm{mg} / \mathrm{dL}$ (77.3 percent), and plasma IL-6 $\geq 3.3 \mathrm{pg} / \mathrm{mL}(81.8$ percent) had LVH (Table V).

\section{Discussion}

While CV complications are the main cause of morbidity and mortality in PD patients, ${ }^{1)} \mathrm{LVH}$ is a major predictor of the development of $\mathrm{CV}$ events independent of regular $\mathrm{CV}$ risk factors. ${ }^{2)} \mathrm{LVH}$ was detected in a substantial proportion of patients. Parameters related to the hydration status, glucose load, and inflammation were found to be possible predictors of the presence of LVH. These parameters include HbA1c, PGLI, FO, plasma BNP, hsCRP, and IL-6. The majority of patients with values $\geq$ the determined cutoffs of these parameters had LVH (Table IV) (Figure).

Previous studies have showed that the RRF plays a pivotal role in the control of hydration status in PD patients. The association between LVH and RRF was determined in earlier studies in this population. Recently, Atas, et al reported that a decrease in daily urine volume in PD patients on maintenance APD was associated with LVH. ${ }^{9)}$ In the current study, LVH was detected in $57.9 \%$ of patients and the LVMI was negatively correlated with daily urine volume $(r=-0.41, P=0.03)$. Recently, Inal, et al reported similar results: 58 percent of $P D$ patients had LVH and the mean LVMI was negatively correlated with daily urine volume in PD patients $(r=-0.568, P=$ $0.001)^{10)}$

Increased peritoneal permeability can be associated with ultrafiltration failure and over hydration status. In such situa-

Table IV. Continuous Variables that Predict the Presence of LVH (Obtained by Applying ROC Curve)

\begin{tabular}{|c|c|c|c|c|c|}
\hline \multirow{2}{*}{ Variable } & \multirow{2}{*}{ AUC } & \multirow{2}{*}{$\mathrm{SE}$} & \multirow{2}{*}{ Asymptotic significance } & \multicolumn{2}{|c|}{ Asymptotic $95 \%$ CI } \\
\hline & & & & Lower Bound & Upper Bound \\
\hline $\mathrm{FO}(\mathrm{L})$ & 0.86 & 0.06 & $<0.001$ & 0.74 & 0.98 \\
\hline Plasma BNP (pg/mL) & 0.88 & 0.05 & $<0.001$ & 0.78 & 0.99 \\
\hline $\operatorname{HbA} 1 \mathrm{c}(\%)$ & 0.84 & 0.07 & $<0.001$ & 0.70 & 0.98 \\
\hline PGLI (g/kg/day) & 0.78 & 0.08 & 0.005 & 0.62 & 0.93 \\
\hline Plasma hsCRP (mg/dL) & 0.89 & 0.05 & $<0.001$ & 0.78 & 0.99 \\
\hline Plasma IL-6 (pg/mL) & 0.87 & 0.06 & $<0.001$ & 0.75 & 0.99 \\
\hline
\end{tabular}

LVMI indicates left ventricular mass index; ROC, receiver operating characteristics; AUC, area under curve; SE, standard error; FO, fluid overload; BNP, plasma brain natriuretic peptide; and PGLI, peritoneal glucose load index. 

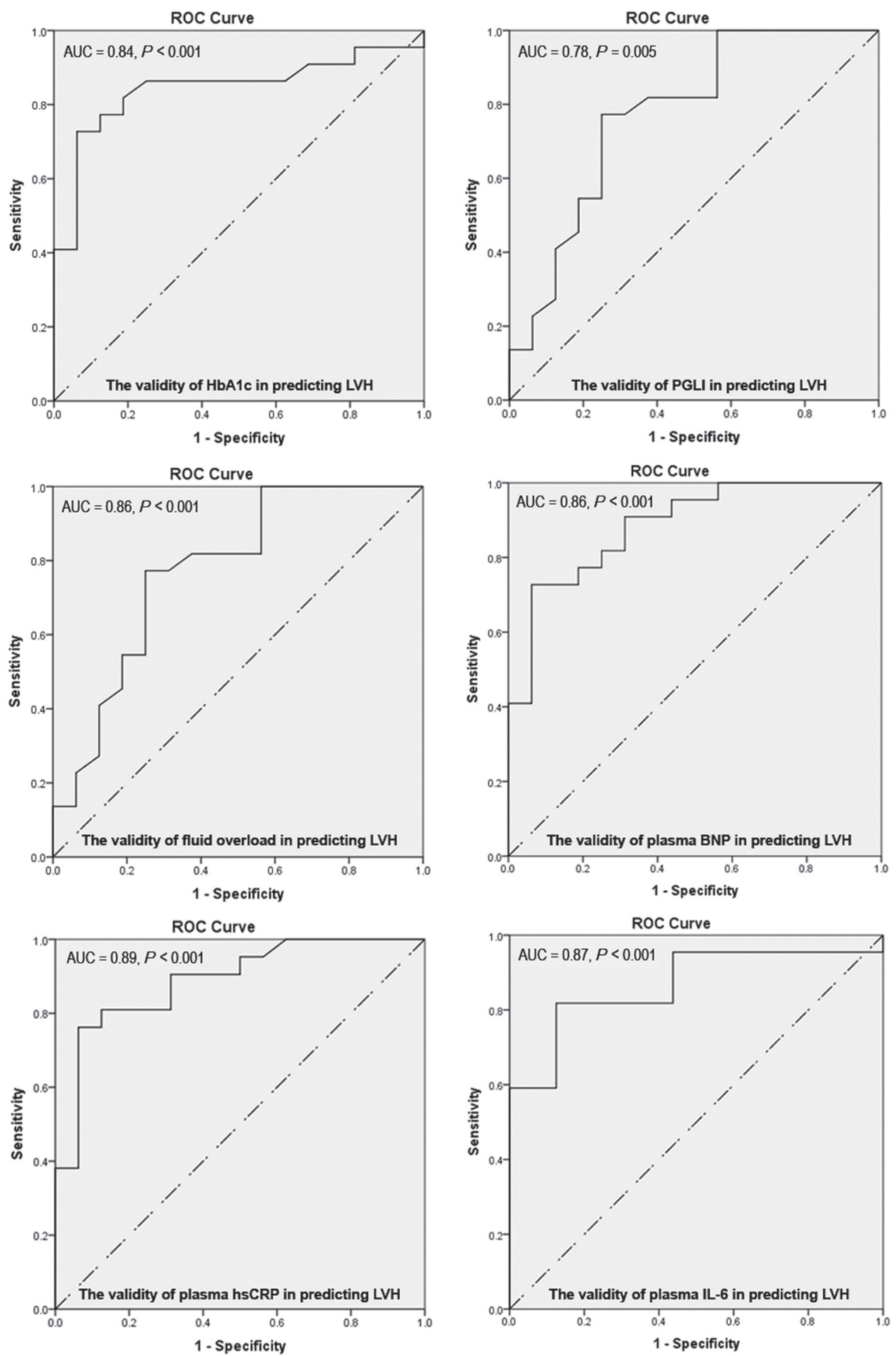

Figure. ROC curves were used to assess the validity of the independent risk factors (HbA1c, PGLI, FO, plasma BNP, plasma hsCRP and IL-6) in predicting LVH. The results showed that all these variables appear to be possible predictors of LVH.

tions, APD with a short dwelling time and frequent exchange of PD solutions may be selected in order to increase ultrafiltration volume. In the present study only stable patients on maintenance PD $\geq 24$ months were included. Patients with ultrafil- tration failure were excluded.

No differences in LVMI were found between patients on maintenance CAPD or APD nor between HAT or LAT patients. No statistically significant correlation was found be- 
Table V. Cutoffs of the Predictors of LVH

\begin{tabular}{|c|c|c|c|c|c|c|c|c|c|c|}
\hline \multirow{2}{*}{ Variable } & \multirow{2}{*}{ Levels } & \multicolumn{2}{|c|}{ Normal LVMI } & \multicolumn{2}{|c|}{ Increased LVMI } & \multicolumn{2}{|c|}{ Total } & \multirow{2}{*}{$\begin{array}{c}\text { Relation } \\
P\end{array}$} & \multicolumn{2}{|c|}{ Agreement } \\
\hline & & $n$ & $\%$ & $n$ & $\%$ & $n$ & $\%$ & & Kappa & $P$ \\
\hline \multirow[t]{2}{*}{ HbAlc (\%) } & $<7.5$ & 15 & $93.8 \%$ & 6 & $27.3 \%$ & 21 & $55.3 \%$ & \multirow[t]{2}{*}{$<0.001$} & \multirow[t]{2}{*}{0.638} & \multirow[t]{2}{*}{$<0.001$} \\
\hline & $\geq 7.5$ & 1 & $6.3 \%$ & 16 & $72.7 \%$ & 17 & $44.7 \%$ & & & \\
\hline \multirow[t]{2}{*}{ PGLI (g/kg/day) } & $<3.2$ & 12 & $75.0 \%$ & 5 & $22.7 \%$ & 17 & $44.7 \%$ & \multirow[t]{2}{*}{0.003} & \multirow[t]{2}{*}{0.518} & \multirow[t]{2}{*}{0.001} \\
\hline & $\geq 3.2$ & 4 & $25.0 \%$ & 17 & $77.3 \%$ & 21 & $55.3 \%$ & & & \\
\hline \multirow[t]{2}{*}{ Fluid overload (L) } & $<1.7$ & 15 & $93.8 \%$ & 6 & $27.3 \%$ & 21 & $55.3 \%$ & \multirow[t]{2}{*}{$<0.001$} & \multirow[t]{2}{*}{0.638} & \multirow[t]{2}{*}{$<0.001$} \\
\hline & $\geq 1.7$ & 1 & $6.3 \%$ & 16 & $72.7 \%$ & 17 & $44.7 \%$ & & & \\
\hline \multirow[t]{2}{*}{$\mathrm{BNP}(\mathrm{pg} / \mathrm{mL})$} & $<330$ & 15 & $93.8 \%$ & 6 & $27.3 \%$ & 21 & $55.3 \%$ & \multirow[t]{2}{*}{$<0.001$} & \multirow[t]{2}{*}{0.638} & \multirow[t]{2}{*}{$<0.001$} \\
\hline & $\geq 330$ & 1 & $6.3 \%$ & 16 & $72.7 \%$ & 17 & $44.7 \%$ & & & \\
\hline \multirow[t]{2}{*}{ CRP (mg/dL) } & $<7.5$ & 15 & $93.8 \%$ & 5 & $22.7 \%$ & 20 & $54.1 \%$ & \multirow[t]{2}{*}{$<0.001$} & \multirow[t]{2}{*}{0.679} & \multirow[t]{2}{*}{$<0.001$} \\
\hline & $\geq 7.5$ & 1 & $6.3 \%$ & 17 & $77.3 \%$ & 17 & $45.9 \%$ & & & \\
\hline \multirow[t]{2}{*}{ IL-6 (pg/mL) } & $<3.3$ & 14 & $87.5 \%$ & 4 & $18.2 \%$ & 18 & $47.4 \%$ & \multirow[t]{2}{*}{0.003} & \multirow[t]{2}{*}{0.518} & \multirow[t]{2}{*}{0.001} \\
\hline & $\geq 3.3$ & 2 & $12.5 \%$ & 18 & $81.8 \%$ & 20 & $52.6 \%$ & & & \\
\hline
\end{tabular}

LVH indicates left ventricular hypertrophy; LVMI, left ventricular mass index; PGLI, peritoneal glucose load index, and BNP, plasma brain natriuretic peptide.

tween D/P creatinine values and LVMI. Similar results were reported by Tonbul, et al. ${ }^{11)}$

$\mathrm{HbA} 1 \mathrm{c}$ is a significant risk factor for all-cause mortality. ${ }^{7)}$ Despite the limitations of $\mathrm{HbAlc}$ in making therapeutic decisions in PD patients, clinically it has been advised to achieve an HbA1c of $<7 \%$. ${ }^{8)}$ High PGLI is usually accompanied by glucose absorption from the peritoneal cavity, resulting in harmful effects on glycemic control and lipid profile, and stimulation of the inflammatory process. ${ }^{9-11)}$ These effects appear to be associated with higher mortality. ${ }^{9-11)}$ Diabetes mellitus itself is a major $\mathrm{CV}$ risk factor in this population. ${ }^{1)}$ Blood hyperviscosity is significantly higher in individuals with poor glycemic control. ${ }^{12)}$ LVM was found to be related to blood viscosity. ${ }^{13,14)}$

Prolonged exposure of the peritoneal membrane to glucose, glucose degradation products (GDPs), advanced glycation end products (AGEs), and the non-physiological $\mathrm{pH}$ of the conventional PD solutions all produce peritoneal cumulative damage leading to increased peritoneal permeability and to the development of FO, elevated plasma BNP levels, hypertension, and $\mathrm{LVH}^{15,16)}$ Plasma BNP levels that reflect changes in hydration status are considered a cardiac biomarker and contribute to prognosis in PD patients. ${ }^{17)}$ Moreover, FO implies use of more hypertonic glucose based PD solutions (GBPDS) that interfere with glycemic control and peritoneal membrane integrity leading to progressive fluid accumulation and stimulation of the inflammatory process.

Inflammation promotes neoangiogenesis, generation of profibrotic factors such as transforming growth factor beta, progressive increase in peritoneal permeability, loss of ultrafiltration and more fluid accumulation. ${ }^{18,19)}$ Inflammation also contributes to the development of endothelial dysfunction, atherosclerosis, and vascular calcification through the secretion of acute phase proteins and cytokines, the activation of complement, and immune cell recruitment. ${ }^{18)}$ Moreover, inflammation is accompanied by hypoalbuminemia and a reduction in oncotic pressure, which may contribute to bowel wall edema that leads to increased gut permeability and elevated endotoxin levels. ${ }^{19-21)}$ Chronic inflammation is considered a promoting factor for the development of LVH and a very powerful predictor for the development of CV disease and mortality in PD patients. $^{22-25)}$

Because the majority of PD patients with HbA1c, PGLI,
FO, plasma BNP, hsCRP, or IL- 6 values $\geq$ the determined cutoffs had LVH, efforts should be made to reduce the peritoneal glucose load, to improve the hydration status and to attenuate the inflammatory process in order to reduce the risk of cardiovascular complications among PD patients.

Although the results showed that HbA1c, PGLI, FO, plasma BNP, hsCRP, and IL-6 can predict the presence of LVH, PGLI seems to be the most simple, inexpensive, and practical method to predict the presence of LVH because it can be applied and calculated at the bedside.

Adhering to a PD regimen utilizing biocompatible, glucose free PD solutions together with strict glycemic control, targeting for adequate ultrafiltration, reducing sodium and fluid intake, using loop diuretics, preserving the RRF, achieving blood pressure targets, and encouraging regular exercise will all contribute to substantial reductions in the PGL, FO, inflammation, and LVM.

PD is considered the most cost-effective dialysis therapy, has the major advantage of being a home dialysis therapy, and has a positive impact on quality of life. Although PD is a key method of renal replacement therapy and could be used to treat at least 15 to 20 percent of dialysis patients, the percentage of patients treated with PD is still low (in Europe, ranging from 4-11 percent). From the medical perspective, the outcomes of hemodialysis and PD are equivalent, and some specific patient groups, eg. the young, may even gain by starting their renal replacement therapy on PD.

At the beginning of a new era of encouraging and promoting PD, the contribution of PGL, FO, and inflammation to the development of LVH shown herein raises the possibility that simple measures including periodic monitoring of the peritoneal glucose load, hydration status, and inflammation markers may represent a potential therapeutic target in the prevention of cardiovascular morbidity and mortality of PD patients.

Limitations: The study was performed in one center and included a small number of patients. Multicenter randomized control trials are needed to confirm these results.

Conclusions: HbA1c, PGLI, FO, plasma BNP, hsCRP, and IL-6 seem to be powerful predictors of LVH in PD patients. Efforts should be made to reduce the peritoneal glucose load, to improve the hydration status and to attenuate the inflamma- 
tory process in order to reduce the risk of the development of $\mathrm{LVH}$ in this population.

\section{Disclosure}

The authors report there are no conflicts of interest in this work

\section{REFERENCES}

1. Locatelli F, Covic A, Chazot C, et al. Hypertension and cardiovascular risk assessment in dialysis patients. Nephrol Dial Transplant 2000; 15: 69-80. (Review)

2. Levy D, Garrison RJ, Savage DD, Kannel WB, Castelli WP. Prognostic implications of echocardiographically determined left ventricular mass in the Framingham Heart Study. N Engl J Med 1990; 322: 1561-6.

3. Van Olden RW, Krediet RT, Struijk DG, Arisz L. Measurement of residual renal function in patients treated with continuous ambulatory peritoneal dialysis. J Am Soc Nephrol 1996; 7: 745-50.

4. Wang AY, Lam CW, Wang M, et al. Diagnostic potential of serum biomarkers for left ventricular abnormalities in chronic peritoneal dialysis patients. Nephrol Dial Transplant 2009; 24: 1962-9.

5. Moissl UM, Wabel P, Chamney PW, et al. Body fluid volume determination via body composition spectroscopy in health and disease. Physiol Meas 2006; 27: 921-33.

6. Devereux RB, Alonso DR, Lutas EM, et al. Electrocardiographic assessment of left ventricular hypertrophy: comparison to necropsy findings. Am J Cardiol 1986; 57: 450-8.

7. Lang RM, Bierig M, Devereux RB, et al. Recommendations for chamber quantification: a report from the American Society of Echocardiography's Guidelines and Standards Committee and the Chamber Quantification Writing Group, developed in conjunction with the European Association of Echocardiography, a branch of the European Society of Cardiology. J Am Soc Echocardiogr 2005; 18: 1440-63.

8. Ghali JK, Liao Y, Simmons B, Castaner A, Cao G, Cooper RS The prognostic role of left ventricular hypertrophy in patients with or without coronary artery disease. Ann Intern Med 1992; 117 831-6.

9. Ataş N, Erten Y, Okyay GU, et al. Left ventricular hypertrophy and blood pressure control in automated and continuous ambulatory peritoneal dialysis patients. Ther Apher Dial 2014; 18: 297 304.

10. Inal S, Erten Y, Okyay GU, et al. Association between bioimpedance analysis parameters and left ventricular hypertrophy in peritoneal dialysis patients. Int Urol Nephrol 2014; 46: 1851-6.

11. Tonbul Z, Altintepe L, Sözlü C, Yeksan M, Yildiz A, Türk S. The association of peritoneal transport properties with 24-hour blood pressure levels in CAPD patients. Perit Dial Int 2003; 23: 46-52.

12. Chen KH, Lin JL, Lin-Tan DT, et al. Glycated hemoglobin predicts mortality in nondiabetic patients receiving chronic peritoneal dialysis. Am J Nephrol 2010; 32: 567-74.
13. Chiu YW, Mehrotra R. Can we reduce the cardiovascular risk in peritoneal dialysis patients? Indian J Nephrol 2010; 20: 59-67.

14. Duong U, Mehrotra R, Molnar MZ, et al. Glycemic control and survival in peritoneal dialysis patients with diabetes mellitus. Clin J Am Soc Nephrol 2011; 5: 1041-8.

15. Grodstein GP, Blumenkrantz MJ, Kopple JD, Moran JK, Coburn JW. Glucose absorption during continuous ambulatory peritoneal dialysis. Kidney Int 1981; 19: 564-7.

16. Fortes PC, de Moraes TP, Mendes JG, Stinghen AE, Ribeiro SC, Pecoits-Filho R. Insulin resistance and glucose homeostasis in peritoneal dialysis. Perit Dial Int 2009; 29: S145-8. (Review)

17. Velcheva I, Damianov P, Mantarova S, Antonova N. Hemorheology and heart rate variability in patients with diabetes mellitus type 2. Clin Hemorheol Microcirc 2011; 49: 513-8.

18. Hassan K, Roguin N, Kaganov Y, Hasan S, Kristal B. Effect of erythropoietin therapy on red cells filterability and left ventricular mass in predialysis patients. Ren Fail 2005; 27: 177-82.

19. Devereux RB, Drayer JI, Chien S, et al. Whole blood viscosity as a determinant of cardiac hypertrophy in systemic hypertension. Am J Cardiol 1984; 54: 592-5.

20. Krediet RT, Zuyderhoudt FMJ, Boeschoten EW, Arisz L. Peritoneal permeability to proteins in diabetic and non diabetic continuous ambulatory peritoneal dialysis patients. Nephron 1986; 42: $133-40$.

21. Vonesh EF, Snyder JJ, Foley RN, Collins AJ. Mortality studies comparing peritoneal dialysis and hemodialysis: what do they tell us? Kidney Int Suppl 2006: S3-11. (Review)

22. Crepaldi C, Lamas EI, Martino FK, et al. Bioimpedance and brain natriuretic peptide in peritoneal dialysis patients. Contrib Nephrol 2012; 178: 174-81. (Review)

23. Vicenté-Martínez M, Martínez-Ramírez L, Muñoz R, et al. Inflammation in patients on peritoneal dialysis is associated with increased extracellular fluid volume. Arch Med Res 2004; 35: 2204.

24. Lundsgaard-Hansen P, Blauhut B. Relation of hypoxia and edema of the intestinal wall and skin to colloid osmotic pressure. Anaesthesist 1988; 37: 112-9. (German)

25. Gonçalves S, Pecoits-Filho R, Perreto S, et al. Associations between renal function, volume status and endotoxaemia in chronic kidney disease patients. Nephrol Dial Transplant 2006; 21: 278894.

26. Yu Z, Tan BK, Dainty S, Mattey DL, Davies SJ. Hypoalbuminaemia, systemic albumin leak and endothelial dysfunction in peritoneal dialysis patients. Nephrol Dial Transplant 2012; 27: 4437-45.

27. Zimmermann J, Herrlinger S, Pruy A, Metzger T, Wanner C. Inflammation enhances cardiovascular risk and mortality in hemodialysis patients. Kidney Int 1999; 55: 648-58.

28. Ducloux D, Bresson-vautrin C, Kribs M, Abdelfatah A, Chalopin JM. C-reactive protein and cardiovascular disease in peritoneal dialysis patients. Kidney Int 2002; 62: 1417-22.

29. Monfared A, Salari A, Kazemnezhad E, et al. Association of left ventricular hypertrophy with high-sensitive C-reactive protein in hemodialysis patients. Int Urol Nephrol 2013; 45: 1679-86.

30. van der Walt C, Malan L, Uys AS, Malan NT. Low grade inflammation and ECG left ventricular hypertrophy in urban African males: The SABPA study. Heart Lung Circ 2013; 22: 924-9. 